\title{
Nonviscous Oblique Stagnation Point Flow towards Riga Plate
}

\author{
Sobia Akbar (D) and Azad Hussain \\ Department of Mathematics, University of Gujrat, Gujrat 50700, Pakistan \\ Correspondence should be addressed to Sobia Akbar; 18026109-004@uog.edu.pk \\ Received 6 May 2021; Revised 11 July 2021; Accepted 5 November 2021; Published 20 November 2021 \\ Academic Editor: Jianguo Wang \\ Copyright (C) 2021 Sobia Akbar and Azad Hussain. This is an open access article distributed under the Creative Commons \\ Attribution License, which permits unrestricted use, distribution, and reproduction in any medium, provided the original work is \\ properly cited.

\begin{abstract}
Purpose. The flow of nonviscous Casson fluid is examined in this study over an oscillating surface. The model of the fluid flow has been inspected in the presence of oblique stagnation point flow. The scrutiny is subsumed for the Riga plate by considering the effects of magnetohydrodynamics. The Riga plate is considered as an electromagnetic lever which carries eternal magnets and a stretching line up of alternating electrodes coupled on a plane surface. We have considered nonboundary layer two-dimensional incompressible flow of the fluid. The fluid flow model is analyzed in the fixed frame of reference. Motivation. The motivation of achieving more suitable results has always been a quest of life for scientists; the capability of determining the boundary layer of flow on aircraft which either stays laminar or turns turbulent has encouraged the researcher to study compressible flow in depth. The compressible fluid with boundary layer flow has been utilized by numerous researchers to reduce skin friction and enhance thermal and convectional heat exchange. Design/Approach/Methodology. The attained partial differential equations will be critically inspected by using suitable similarity transformation to transform these flows thrived equations into higher nonlinear ordinary differential equations (ODE). Then, these equations of motion are intercepted by mathematical techniques such as the bvp $4 \mathrm{c}$ method in Maple and Matlab. The graphical and tabular representation of different parameters is also given. Findings. The behavior of $\beta$ and modified Hartmann number $M$ increases by positively increasing the values of both parameters for $F(\eta)$, while $\omega$ decreases with increasing the values of $\omega$ for $F(\eta)$. The graph of $\beta$ shows upward behavior for distinct values for both $G(\eta)$ and $G^{\prime}(\eta)$ for velocity portray. Prandtl number and $\beta$ for the temperature profile of $\theta(\eta)$ and $\theta_{1}(\eta)$ goes downward with increasing parameters.
\end{abstract}

\section{Introduction}

The idea of stagnation point flow to find the exact solution of the Navier-Stokes equations was earlier discussed by Hiemenz [1] The applications of heat flow of stagnation point flows are impartially manifested in paper manufacture, melt spinning process, revolving fibers, continuous molding, and crystal puffing, given by Mehmood et al. [2] In the divination of skin friction in addition to mass or heat transfer near to stagnation zone of bodies in transpiration cooling, great speed movements, project of thrust compartment, radial diffusers, thermal oil repossession, and drag decrease along with several substantial control have considerable physical consequences [3].

The flows of magnetohydrodynamic electrical conducting fluids have apprehended the notice of scientists and researchers as they have numeral utilizations in industrial and engineering fields. The skin friction and heat transfer coefficient have higher results for turbulent flow as compared to laminar flow; any numerical technique that can be employed to enhance the stability of laminar flow is worth investigating. However, the properties of high electrical conductivity are not effective in all fluids. Ibrahim [4] analyzed the properties of nonlinear MHD flow with thermal radiations of nanofluid regulated with a stretching sheet in the zone of stagnation point flow with the effects of convective heat transfer. Li et al. [5] studied mannerisms of MHD flow of non-Fourier nanofluid with heat conduction determined by the stretched surface. The radiative flow of MHD nanofluid with the effects of heat transfer regarding a stretching surface was analyzed by Ghasemi et al. [6]. The micropolar boundary layer flow of nanofluid with stretching sheet was described by Turkyilmazoglu [7].

Wall-parallel Lorentz force is processed by using the Riga plate, as Riga plate is a compound of alternating 
electrodes and persistent magnets connected in a flat surface. In this regulation, first strive was taken into account to produce a wall-parallel Lorentz force which was discussed by Gailitis et al. [8]. In this study, it is initiated that, by suing electromagnetic body forces, the electrically conducting fluid flows can be handled to repay the momentum scarcity in the boundary layer. It can be worn as a sufficient factor for decline of skin friction and pressure drag of submarines circumvents the segregation of the boundary layer.

\section{Problem Statement}

Consider the unsteady incompressible flow model for non-Newtonian Casson fluid with the Riga plate. The unsteadiness in the fluid has been induced by the timedependent flow. The model geometry is shown in Figure 1(a). In the rectangular coordinate system, $u$ and $v$ are velocity components along $x$ - and $y$-axis. The plate vacillating in its own plan and the flow of the nanofluid distract obliquely on it. The fluid is in the upper half of the plane $y \geq 0$. The stress tensor for the given flow field is defined as

$$
T=-\mathrm{PI}+\mu_{\beta}\left(1+\frac{1}{\beta}\right) A_{1}
$$

\section{Mathematical Analysis}

The continuity equation for the given problem is

$$
\frac{\partial u}{\partial x}+\frac{\partial v}{\partial y}=0
$$

The momentum equations for the given flow field is expressed as

$$
\begin{aligned}
\rho\left(\frac{\partial u}{\partial t}+u \frac{\partial u}{\partial x}+v \frac{\partial u}{\partial y}\right)= & -\frac{\partial P}{\partial x}+\mu_{\beta}\left(1+\frac{1}{\beta}\right)\left(\frac{\partial^{2} u}{\partial x^{2}}+\frac{\partial^{2} v}{\partial y^{2}}\right) \\
& +\frac{\pi J_{0} M_{0}}{8} e^{((-\pi / a) y)}, \\
\rho\left(\frac{\partial v}{\partial t}+u \frac{\partial v}{\partial x}+v \frac{\partial v}{\partial y}\right)= & -\frac{\partial P}{\partial y}+\mu_{\beta}\left(1+\frac{1}{\beta}\right)\left(\frac{\partial^{2} u}{\partial x^{2}}+\frac{\partial^{2} v}{\partial y^{2}}\right) .
\end{aligned}
$$

Similarly, the energy equation is given as

$$
\rho C_{P}\left(\frac{\partial}{\partial t}+u \frac{\partial}{\partial x}+v \frac{\partial}{\partial y}\right) T=k \mu_{\beta}\left(1+\frac{1}{\beta}\right)\left(\frac{\partial^{2}}{\partial x^{2}}+\frac{\partial^{2}}{\partial y^{2}}\right) T
$$

where the current density width of magnet is $J_{0}$, specific heat is $C_{P}$, and the magnetization of permanent magnets is $M_{0}$.

Now, we are going to introduce the occurrence of the stream function as

$$
\begin{gathered}
u=\frac{\partial \Psi}{\partial y} \\
v=-\frac{\partial \Psi}{\partial x} .
\end{gathered}
$$

By using stream function in equations (3)-(5), we have

$$
\begin{gathered}
\frac{\partial}{\partial t}\left(\frac{\partial^{2} \Psi}{\partial x^{2}}+\frac{\partial^{2} \Psi}{\partial y^{2}}\right)+\frac{\partial \Psi}{\partial y}\left(\frac{\partial^{3} \Psi}{\partial x \partial y^{2}}+\frac{\partial^{3} \Psi}{\partial x^{3}}\right) \\
-\frac{\partial \Psi}{\partial x}\left(\frac{\partial^{3} \Psi}{\partial y^{3}}+\frac{\partial^{3} \Psi}{\partial y \partial x^{2}}\right)-\frac{\mu_{\beta}(1+(1 / \beta))}{\rho} \\
\left(\frac{\partial^{4} \Psi}{\partial x^{4}}+2 \frac{\partial^{4} \Psi}{\partial x^{2} \partial y^{2}}+\frac{\partial^{4} \Psi}{\partial y^{4}}\right)=0 \\
\frac{\partial}{\partial t}\left(\nabla^{4} \Psi\right)-\left[\frac{\partial \Psi}{\partial x} \frac{\partial}{\partial y}\left(\nabla^{2} \Psi\right)-\frac{\partial \Psi}{\partial y} \frac{\partial}{\partial x}\left(\nabla^{2} \Psi\right)\right] \\
-\frac{\mu_{\beta}(1+(1 / \beta))}{\rho} \nabla^{2} \Psi=0, \\
\frac{k \mu_{\beta}(1+(1 / \beta))}{\rho C_{P}}\left(\frac{\partial^{2} T}{\partial x^{2}}+\frac{\partial^{2} T}{\partial y^{2}}\right)-\frac{\partial T}{\partial t}-\frac{\partial \Psi}{\partial y} \frac{\partial T}{\partial x}-\frac{\partial \Psi}{\partial x} \frac{\partial T}{\partial y}=0
\end{gathered}
$$

\section{Fixed Frame of Reference for the Fluid Flow Model}

Conferring to [9], we consider that

$$
\Psi=k[x f(y)+g(y)],
$$

where $k$ is a parameter. We examine that the plate is oscillating at the point $y=0$, and the fluid engaged at the upper half plane $y>0$. The flow function is given by [41] $\Psi=(1 / 2) \gamma y^{2}+x y$.

The above equations can also be written as

$$
\begin{aligned}
& \frac{\mu_{\beta}(1+(1 / \beta))}{\rho} \frac{\mathrm{d}^{3} f}{\mathrm{~d} y^{3}}+a\left(f \frac{\mathrm{d}^{2} f}{\mathrm{~d} y^{2}}-\frac{\mathrm{d} f}{\mathrm{~d} y} \frac{\mathrm{d} f}{\mathrm{~d} y}\right)=-a, \\
& \frac{\mu_{\beta}(1+(1 / \beta))}{\rho} \frac{\mathrm{d}^{3} g}{\mathrm{~d} g^{3}}+a\left(f \frac{\partial^{2} g}{\partial y^{2}}-\frac{\mathrm{d} g}{\mathrm{~d} y} \frac{\mathrm{d} f}{\mathrm{~d} y}\right)-\frac{\partial^{2} g}{\partial y \partial t}=-a .
\end{aligned}
$$

The boundary conditions are given below:

$$
\begin{aligned}
& f(y)=0, f^{\prime(y)}=0, g(y)=0, g^{\prime}(y)=0, \quad \text { at } y=0, \\
& f^{\prime(y)}=1, g^{\prime(y)}=\gamma y, \quad \text { at } y \longrightarrow \infty,
\end{aligned}
$$

where $\gamma$ is the dimensionless number.

We introduce

$$
\begin{aligned}
f(y) & =\sqrt{\frac{v}{a}} F(\eta), \\
g(t, y) & =\frac{v}{a}\left[G_{0}(\eta)+\varepsilon G_{1}(\eta) e^{i \tau}\right],
\end{aligned}
$$




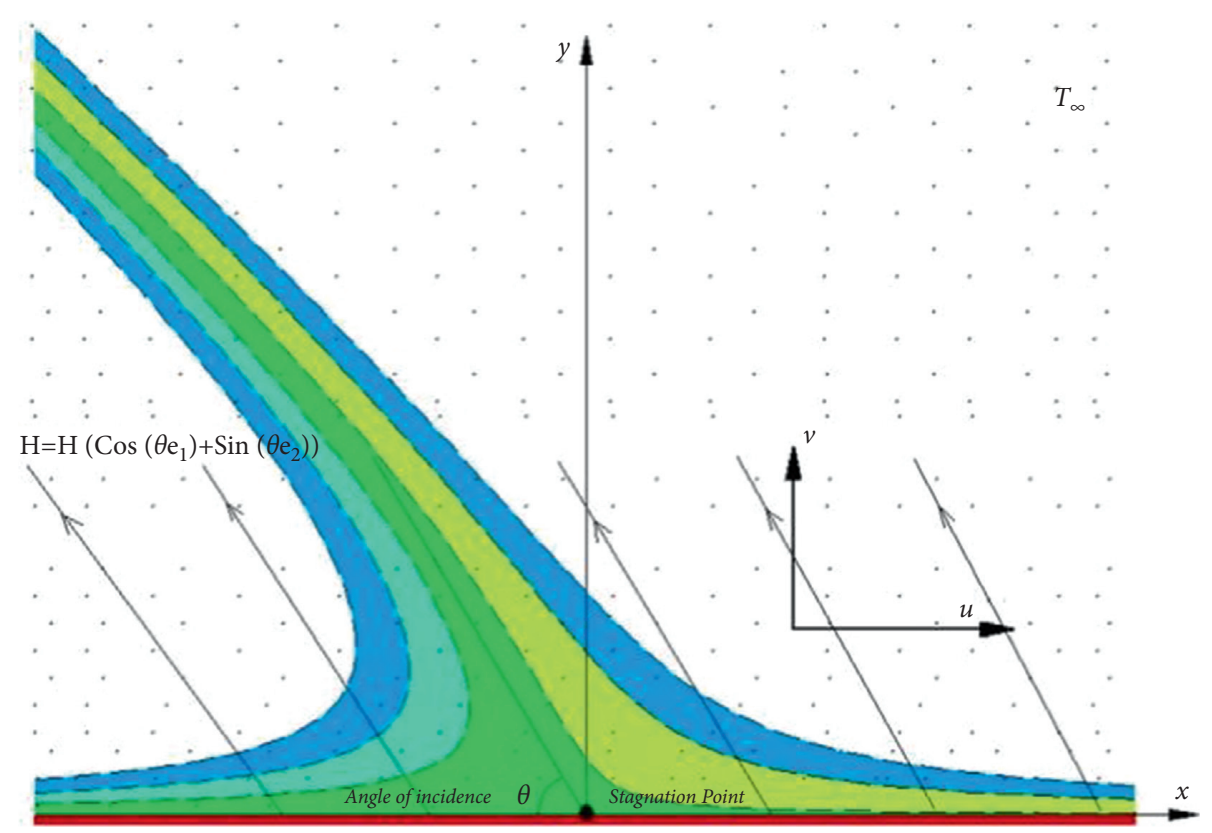

FIgURE 1: Physical geometry of the problem.

where

$$
\begin{aligned}
\tau & =\omega t, \\
\varepsilon & =\frac{U}{\sqrt{ } v k}, \\
\theta(y)+\varepsilon \theta_{1}(y) & =\frac{T-T_{\infty}}{T_{w}-T_{\infty}} .
\end{aligned}
$$

By using the nondimensional form of equations (10) and (11), we get the following form of equations (9), (11), and (12) as follows:

$$
\begin{aligned}
\left(1+\frac{1}{\beta}\right) F^{\prime \prime \prime}+F F^{\prime \prime}-{F^{\prime}}^{2}+1+M e^{(-\omega \eta)} & =0, \\
\left(1+\frac{1}{\beta}\right) G^{\prime \prime \prime}+F G^{\prime \prime}-G^{\prime} F^{\prime} & =0, \\
\left(1+\frac{1}{\beta}\right) G_{1}^{\prime \prime \prime}+G_{1}^{\prime \prime} F-G_{1}^{\prime} F^{\prime}-i \sigma G_{1}^{\prime} & =0, \\
\frac{(1+1 / \beta)}{\operatorname{Pr}} \theta^{\prime \prime}+F \theta^{\prime} & =0,
\end{aligned}
$$

$$
\frac{(1+1 / \beta)}{\operatorname{Pr}} \theta_{1}^{\prime \prime}+F \theta_{1}^{\prime}-i \sigma \theta_{1}=0
$$

The nondimensional boundary conditions for the above all equations (16)-(20) are given below:

$$
\begin{aligned}
& {\left[\begin{array}{c}
F(0)=0, F^{\prime}(0)=0, F^{\prime}(\infty)=1, \\
G(0)=0, G^{\prime}(0)=0, G^{\prime \prime}(\infty)=\gamma, \\
G_{1}(0)=0, G_{1}^{\prime}(0)=1, G_{1}^{\prime \prime}(\infty)=\gamma,
\end{array}\right]} \\
& {\left[\begin{array}{c}
\theta(\infty)=0, \theta(0)=1, \\
\theta_{1}(\infty)=0, \theta_{1}(0)=1 .
\end{array}\right]}
\end{aligned}
$$

\section{Numerical Solution}

The equations which we obtained from the basic governing equations are highly nonlinear which are changed to ODEs numerically. Then, we have solved these equations with the help of Maple software (equations (4) and (11)).

Now, we are going to introduce new scheme of variables to solve these higher order ODEs into $1^{\text {st }}$ order equations, i.e.,

$$
\begin{aligned}
& {\left[F=q_{1}, F^{\prime}=q_{2}, F^{\prime \prime}=q_{3}, F^{\prime \prime \prime}=q_{3}^{\prime},\right.} \\
& G=q_{4}, G^{\prime}=q_{5}, G^{\prime \prime}=q_{6}, G^{\prime \prime \prime}=q_{6}^{\prime}, \\
& G_{1}=q_{7}, G_{1}^{\prime}=q_{8}, G_{1}^{\prime \prime}=q_{9}, G_{1}^{\prime \prime}=q_{9}^{\prime}, \\
& \theta=q_{10}, \theta^{\prime}=q_{11}, \theta^{\prime \prime}=q_{11}^{\prime}, \\
& \left.\theta_{1}=q_{12}, \theta_{1}^{\prime}=q_{13}, \theta_{1}^{\prime \prime}=q_{13}^{\prime}\right] .
\end{aligned}
$$




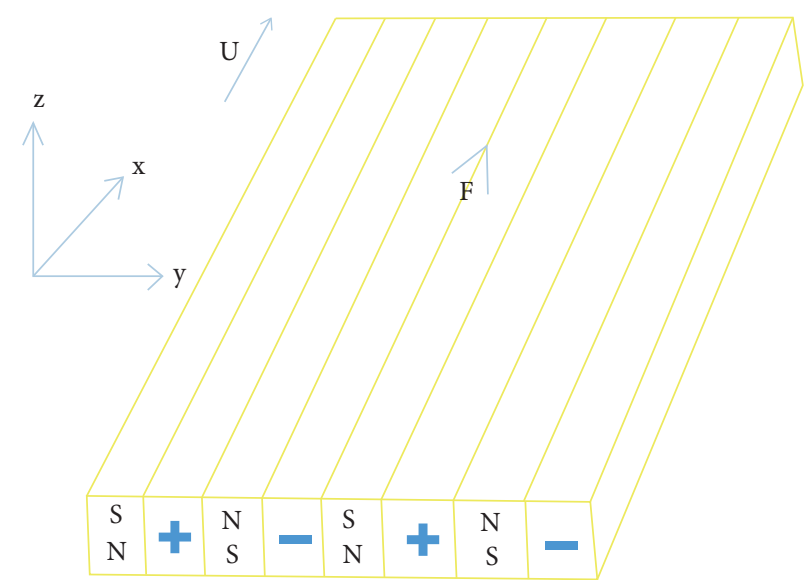

FIgURE 2: Riga plate that persuades Lorentz force opposite to the external free stream.

By using (23), we have the following form of equations

(16)-(20) as

$$
\begin{aligned}
& q_{1}^{\prime}=q_{2}, q_{2}^{\prime}=q_{3}, q_{3}^{\prime}=q_{4}, q_{4}^{\prime}=q_{5}, q_{5}^{\prime}=q_{6}, q_{6}^{\prime}=q_{7}, \\
& q_{7}^{\prime}=q_{8}, q_{8}^{\prime}=q_{9}, q_{9}^{\prime}=q_{10}, q_{10}^{\prime}=q_{11}, q_{11}^{\prime}=q_{12}, q_{12}^{\prime}=q_{13}, \\
& q_{3}^{\prime}=\frac{1}{(1+(1 / \beta))}\left[F^{\prime 2}-F F^{\prime \prime}-1-M e^{(-\omega \eta)}\right], \\
& q_{6}^{\prime}=\frac{1}{(1+(1 / \beta))}\left[G^{\prime} F^{\prime}-F G^{\prime \prime}\right], \\
& q_{9}^{\prime}=\frac{1}{(1+(1 / \beta))}\left[G_{1}^{\prime} F^{\prime}-G_{1}^{\prime \prime} F+i \sigma G_{1}^{\prime}\right], \\
& q_{11}^{\prime}=\frac{\operatorname{Pr}}{(1+(1 / \beta))} F \theta^{\prime}, \\
& q_{13}^{\prime}=\frac{\operatorname{Pr}}{(1+(1 / \beta))}\left[-F \theta_{1}^{\prime}+i \sigma \theta_{1}\right],
\end{aligned}
$$

under appropriate boundary conditions:

$$
\begin{aligned}
w_{1}(0) & =0, w_{1}(\infty)=1, w_{1}(0)=0, w_{4}(0)=0, w_{5}(0)=0, \\
w_{5}(\infty) & =\gamma, w_{7}(0)=0, w_{8}(0)=0, w_{8}(\infty)=\gamma, w_{10}(0)=1, \\
w_{11}(\infty) & =0, w_{12}(0)=1, w_{13}(\infty)=0 .
\end{aligned}
$$

\section{Graphical Discussion}

Newtonian and non-Newtonian fluids are widely used in chemical engineering, bio-chemical engineering, food processing, oil exploration, and medical engineering. In particular, what has been studied most intensely for obvious practical reasons is how heat and momentum are transferred to moving Newtonian and non-Newtonian fluids. The inquisition which we have considered for investigation can be represented graphically by different distinct parameters as stated below. Figure 1 gives the geometry of the given problem for nonviscous behavior of the flow model. Figure 2 represents the Riga plate that persuades Lorentz force opposite to the external free stream. The portray of $\beta$ for the different values of $\beta$, which gives the increasing behavior for $F(\eta)$, is shown in Figure 3. The increasing graph of modified Hartmann number $M$ for $F(\eta)$ is given in Figure 4. Figure 5 illustrates the velocity profile for $\beta$ with different values for $G(\eta)$. The graph increases positively by increasing the values of $\beta$. Figure 6 shows the decreasing graph of $\omega$ for $F(\eta)$. The upward graph of $\beta$ for $G_{1}(\eta)$ is demonstrated for distinct values of $\beta$ in Figure 7 . The illustration of $\beta$ for the 


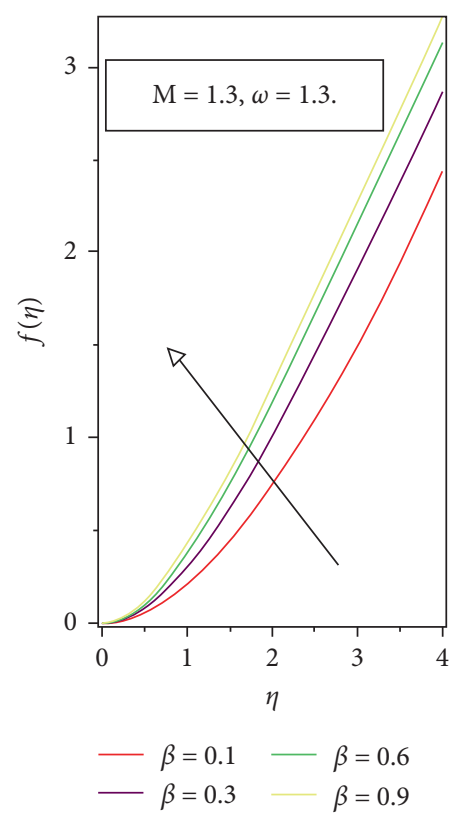

Figure 3: Effects of $\beta$ for $f(\eta)$.

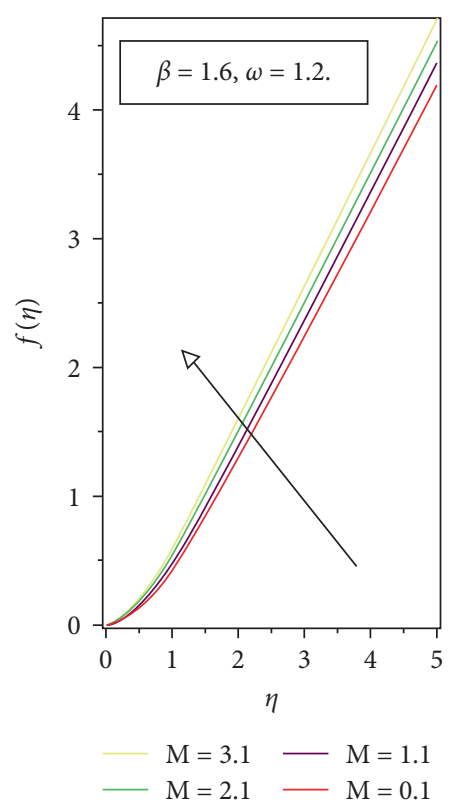

Figure 4: Impact of $M$ for $f(\eta)$.

temperature profile of $\theta_{1}(\eta)$ for positive values of $\beta$ is given in Figure 8. The Prandtl number for high values of $\operatorname{Pr}$ for $\theta_{1}(\eta)$ is given in Figure 9, which goes downwards with increasing Pr. Similarly, the decreasing graphs of $\operatorname{Pr}$ for $\theta(\eta)$ with positive values of the Prandtl number is shown in Figure 10. The portray for temperature of $\beta$ decreasing with increasing the values of $\beta$ for $\theta(\eta)$ represented in Figure 11 The Nusselt number graph of $\beta=0.1,0.3,0.5$ is shown in Figure 12, which demonstrates the upward lines in the

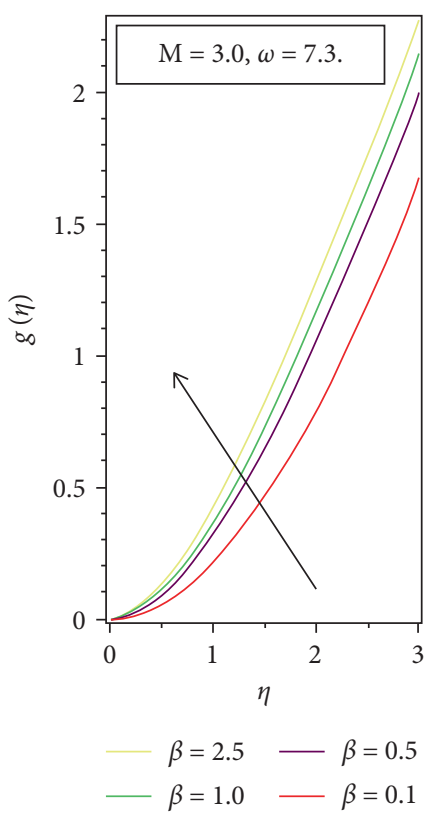

Figure 5: Effects of $\beta$ for $g(\eta)$.

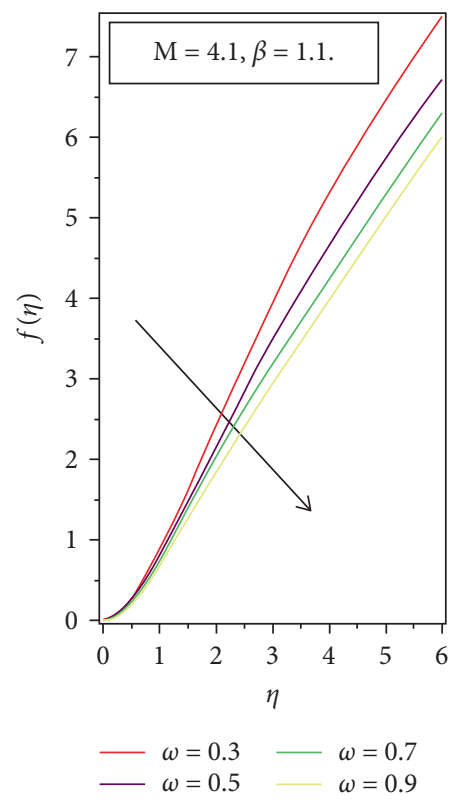

FIgURE 6: Influence of $\omega$ for $f(\eta)$.

graph. Figure 13 describes the unsteady flow for the given fluid model. Figures 14-16 express the three-dimensional portray for the distinct values of $\beta$. Similarly, different values of $M$ show the stream lines graphs in Figures 17-19. Different values of the Nusselt number for $\theta(\eta)$ are represented in Table 1. In Table 2, distinct values of the Nusselt number for $\theta_{1}(\eta)$ are given. Table 3 shows the skin friction coefficient. 


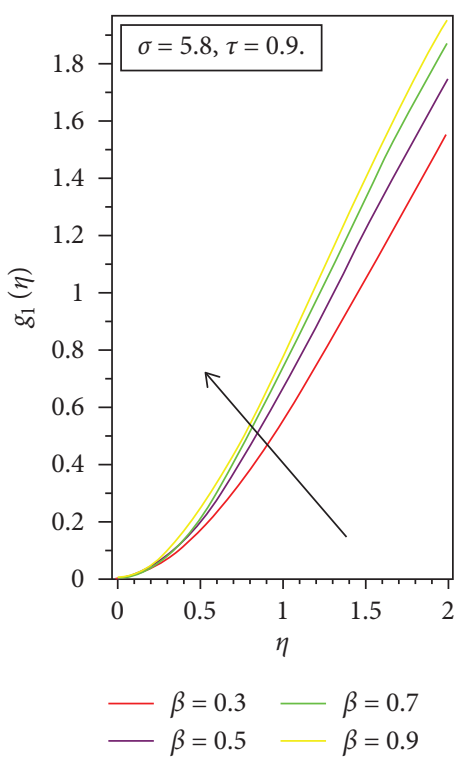

Figure 7: Implementation of $\beta$ for $g(\eta)$.

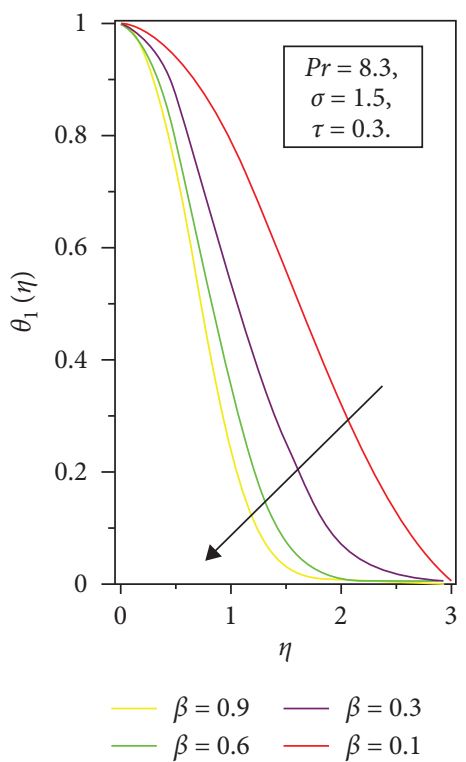

Figure 8: Impact of $\beta$ for $\theta_{1}$.

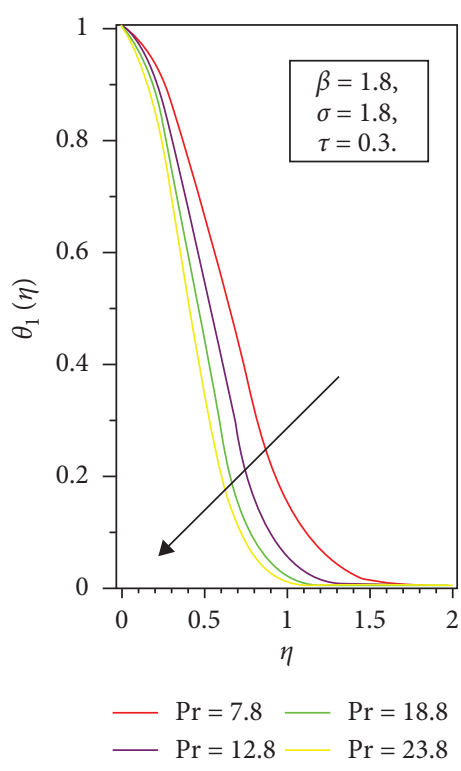

Figure 9: Impact of $\operatorname{Pr}$ for $\theta_{1}$.

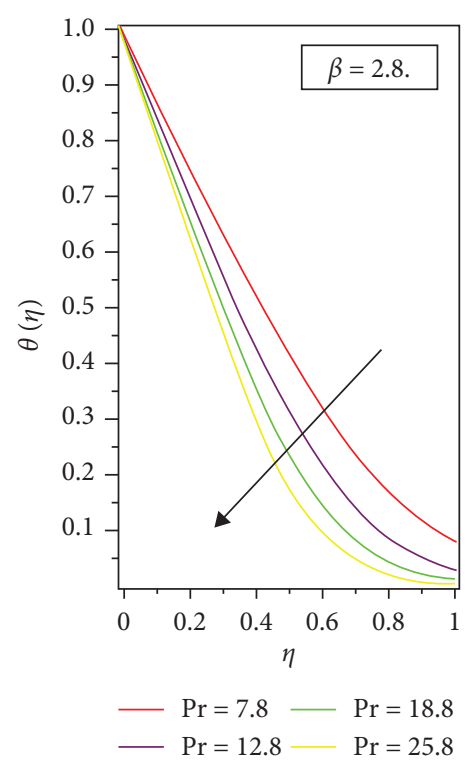

Figure 10: Effects of $\operatorname{Pr}$ for $\theta$. 


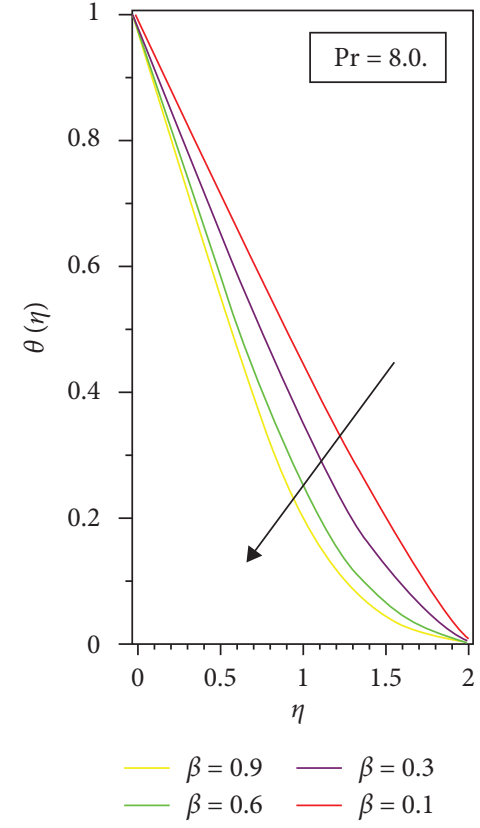

Figure 11: Impact of $\beta$ for $\theta$.

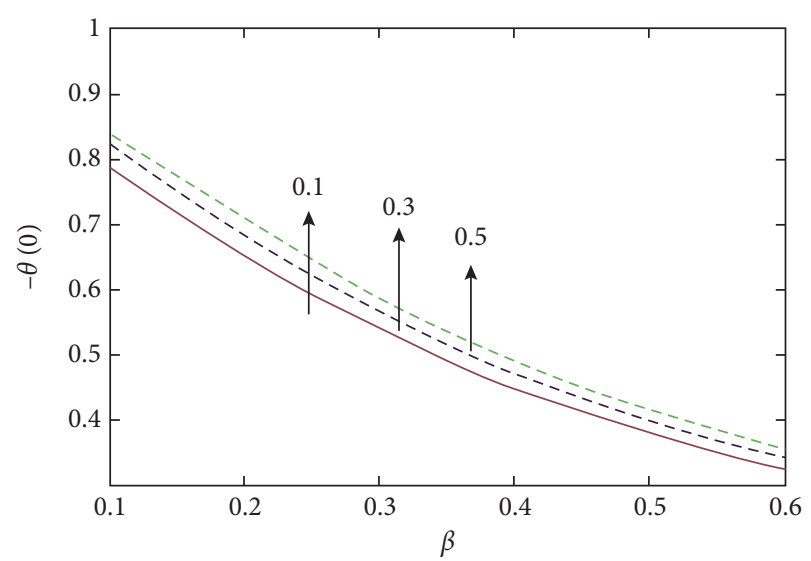

FIGURE 12: Graph showing upward behavior for $\beta$ for the Nusselt number.

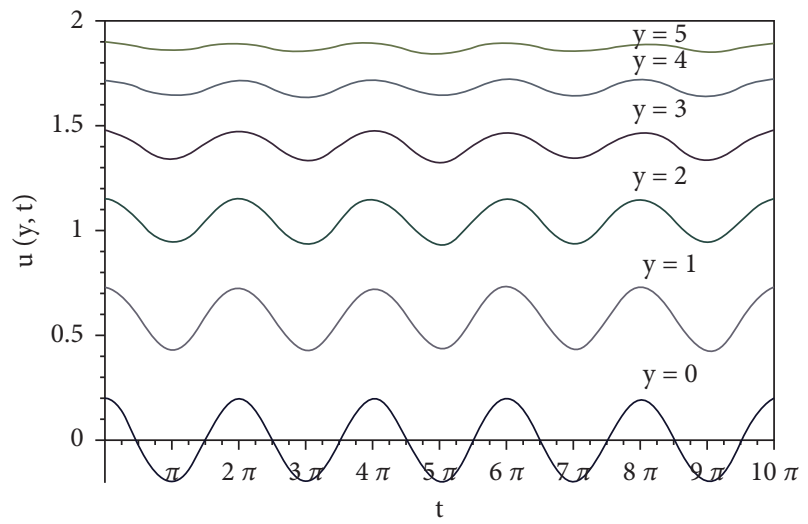

Figure 13: Impact of time-dependent flow on the fluid model.

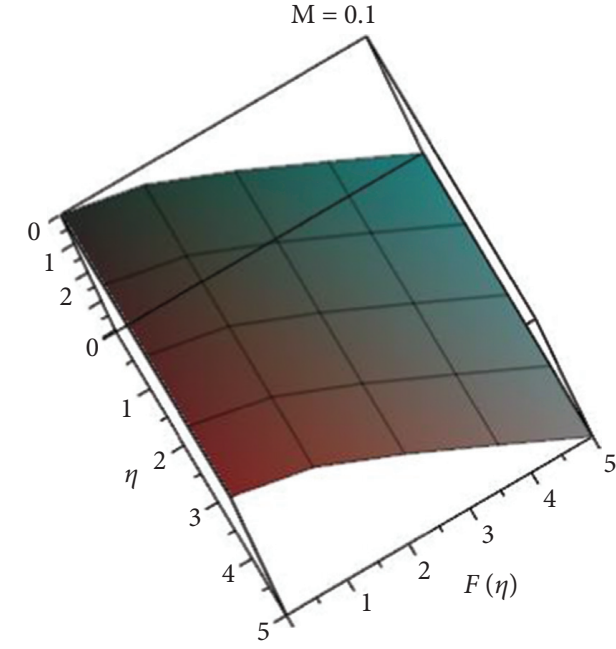

Figure 14: Three-dimensional graph for $M=0.1$.

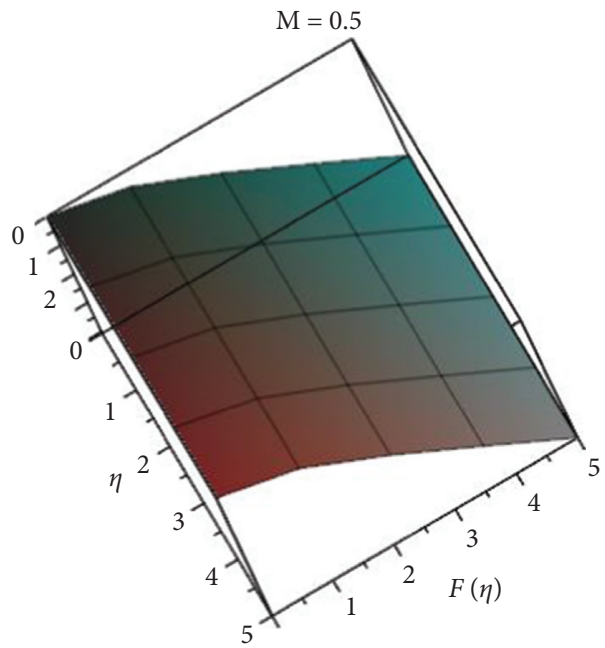

FIgURE 15: Three-dimensional graph for $M=0.5$.

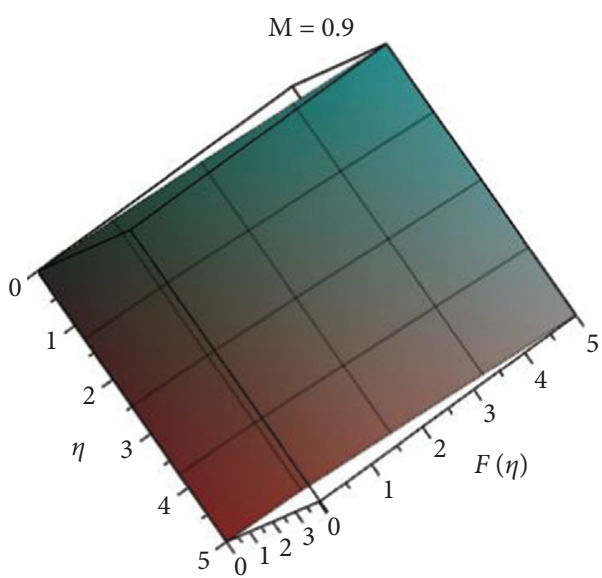

Figure 16: Three-dimensional graph for $M=0.9$. 


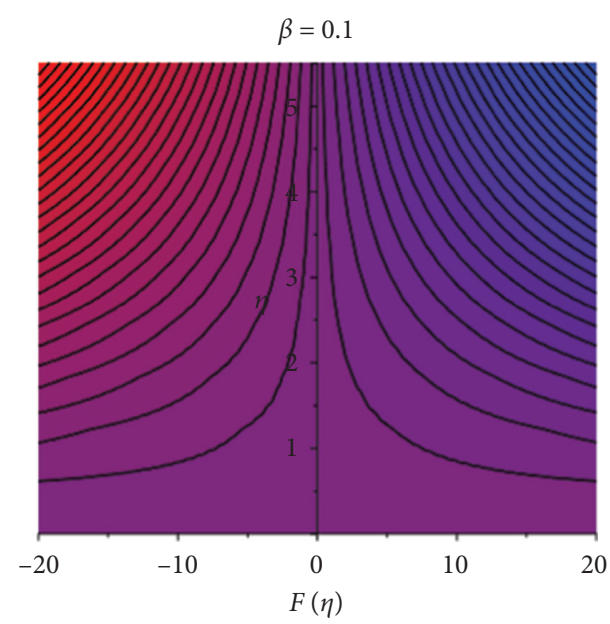

Figure 17: Stream lines for $\beta=0.1$.

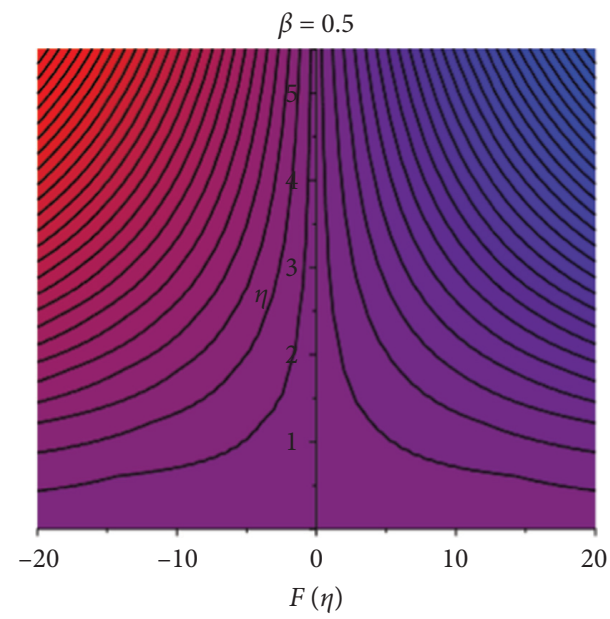

Figure 18: Stream lines for $\beta=0.5$.

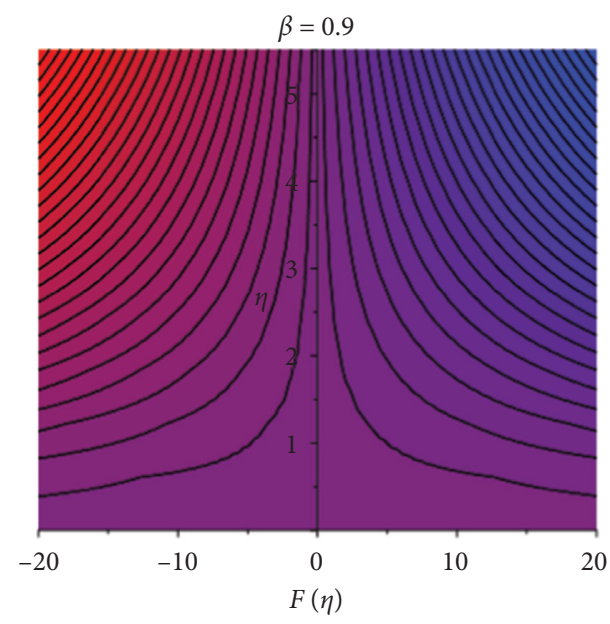

Figure 19: Stream lines for $\beta=0.9$.
TABLE 1: Values for the Nusselt number for $\theta(\eta)$ distinct parameters which are compared with the previous study [10].

\begin{tabular}{lccc}
\hline $\operatorname{Pr}$ & $\beta$ & $-\theta^{\prime}(0)$ & {$[10]$} \\
\hline 7.8 & 0.1 & 1.239958 & 0.664914 \\
7.9 & & 1.245907 & 0.821894 \\
8.0 & & 1.251807 & 1.081942 \\
7.8 & & 1.239958 & 0.664914 \\
& 0.2 & 0.471256 & 0.856256 \\
& 0.3 & 0.620050 & 0.887956 \\
& 0.1 & 1.239958 & 0.856256 \\
\hline
\end{tabular}

Table 2: Values for the Nusselt number for $\theta_{1}(\eta)$ distinct parameters.

\begin{tabular}{lcccc}
\hline $\operatorname{Pr}$ & $\sigma$ & $\beta$ & $-\theta^{\prime}(0)$ & {$[11]$} \\
\hline 7.8 & 1.8 & 1.8 & 0.386920 & 0.665935 \\
8.8 & & & 0.334243 & 0.857260 \\
9.8 & & & 0.325699 & 0.888969 \\
7.8 & & & 0.386920 & 0.665935 \\
& 1.9 & & 0.325827 & 0.674942 \\
& 2.0 & & 0.309536 & 0.831899 \\
& 1.8 & & 0.386920 & 0.665935 \\
& & 1.9 & 0.415894 & 0.082986 \\
& & 2.0 & 0.364278 & 0.375643 \\
& & 1.8 & 0.386920 & 0.665935 \\
\hline
\end{tabular}

TABle 3: Values of $M, \beta$, and $\omega$ for the skin friction coefficient.

\begin{tabular}{lcccc}
\hline$\beta$ & $M$ & $\omega$ & $1 / 2 C_{f} R e$ & {$[12]$} \\
\hline 0.1 & 1.3 & 1.3 & 0.474983 & -0.839302 \\
0.2 & & & 0.638577 & -0.937015 \\
0.3 & & & 0.768523 & -1.053934 \\
0.1 & & & 0.474983 & -0.839302 \\
& 1.4 & & 0.480390 & -0.829415 \\
& 1.5 & & 0.485796 & -0.933832 \\
& 1.3 & & 0.474983 & -0.839302 \\
& & 1.4 & 0.471195 & -1.026499 \\
& & 1.5 & 0.467776 & -0.478302 \\
& & 1.3 & 0.474983 & -0.38643 \\
\hline
\end{tabular}

\section{Concluding Remarks}

We have discussed the unsteady the flow of Casson fluid by assuming the Riga plate over the oscillating surface. The obtained results which are given below:

(1) The behavior of $\beta$ and modified Hartmann number $M$ increase by positively increasing the values of both parameters for $F(\eta)$, while $\omega$ decreases with increasing the values of $\omega$ for $F(\eta)$

(2) The graph of $\beta$ shows upward behavior for distinct values for both $G(\eta)$ and $G^{\prime}(\eta)$ for velocity portray 
(3) The Prandtl number and $\beta$ for the temperature profile of $\theta(\eta)$ and $\theta_{1}(\eta)$ goes downward with increasing parameters

(4) Nusselt number graph for temperature shows an increment

\section{Nomenclature}

$u, v: \quad$ Velocity components [L/T]

$x, y: \quad$ Spatial coordinates [L]

$\psi: \quad$ Stream function $\left[\mathrm{L}^{2} / \mathrm{T}\right]$

$p: \quad$ Pressure field $\left[\mathrm{ML} / \mathrm{T}^{2]}\right.$

$g(y)$ : Shear component of flow

$f(y)$ : Normal component of the flow

$\bar{G}(y)$ : Shear component of angular momentum

$\bar{F}(y)$ : Normal component of angular momentum

$\rho: \quad$ Density of fluid

T: $\quad$ Temperature field, $[\mathrm{K}]$

$\mu$ : Dynamic viscosity of fluid

$\beta$ : $\quad$ Casson fluid flow parameter

$M$ : $\quad$ Riga plate parameter

$\rho C p$ : Heat capacity of fluids

$k$ : $\quad$ Thermal conductivity of fluid $\left[\mathrm{ML} / \mathrm{T}^{3} \mathrm{~K}\right]$.

\section{Data Availability}

The data used to support the findings of the study are available from the corresponding upon request.

\section{Conflicts of Interest}

The authors declare that they have no conflicts of interest.

\section{References}

[1] K. Hiemenz, "Die Grenzschicht an einem in den gleichformigen Flussigkeitsstrom eingetauchten geraden Kreiszylinder," Digitalisierung des Polytechnischen, vol. 326, pp. 321-324, 1911.

[2] R. Mehmood, S. Rana, N. S. Akbar, and S. Nadeem, "Nonaligned stagnation point flow of radiating Casson fluid over a stretching surface," Alexandria Engineering Journal, vol. 57, no. 2, pp. 939-946, 2018.

[3] S. Nadeem, R. Mehmood, and N. S. Akbar, "Optimized analytical solution for oblique flow of a Casson-nano fluid with convective boundary conditions," International Journal of Thermal Sciences, vol. 78, pp. 90-100, 2014.

[4] W. Ibrahim, "Nonlinear radiative heat transfer in magnetohydrodynamic (MHD) stagnation point flow of nanofluid past a stretching sheet with convective boundary condition," Propulsion and Power Research, vol. 4, no. 4, pp. 230-239, 2015.

[5] J. Li, L. Zheng, and L. Liu, "MHD viscoelastic flow and heat transfer over a vertical stretching sheet with CattaneoChristov heat flux effects," Journal of Molecular Liquids, vol. 221, pp. 19-25, 2016.

[6] S. E. Ghasemi, M. Hatami, D. Jing, and D. D. Ganji, "Nanoparticles effects on MHD fluid flow over a stretching sheet with solar radiation: a numerical study," Journal of Molecular Liquids, vol. 219, pp. 890-896, 2016.
[7] M. Turkyilmazoglu, "Flow of a micropolar fluid due to a porous stretching sheet and heat transfer," International Journal of Non-Linear Mechanics, vol. 83, pp. 59-64, 2016.

[8] A. Gailitis, "On the possibility to reduce the hydrodynamic drag of a plate in an electrolyte," Appl. Magnetohydrodynamics, Rep. Inst. Phys. Riga, vol. 13, pp. 143-146, 1961.

[9] I. Khan, M. Y. Malik, A. Hussain, and T. Salahuddin, "Effect of homogenous-heterogeneous reactions on MHD Prandtl fluid flow over a stretching sheet," Results in physics, vol. 7, pp. 4226-4231, 2017.

[10] Rizwana, A. Hussain, S. Nadeem, and S. Nadeem, "MHD oblique stagnation point flow of copper-water nanofluid with variable properties," Physica Scripta, vol. 94, no. 12, p. 125808, 2019.

[11] R. Rizwana, A. Hussain, S. Nadeem, and S. Nadeem, "Series solution of unsteady MHD oblique stagnation point flow of copper-water nanofluid flow towards Riga plate," Heliyon, vol. 6, no. 10, Article ID e04689, 2020.

[12] R. Rizwana, A. Hussain, and S. Nadeem, "Slip effects on unsteady oblique stagnation point flow of nanofluid in a view of inclined magnetic field," Mathematical Problems in Engineering, vol. 2020, Article ID 6580409, 12 pages, 2020. 